\title{
Estado da arte da geografia econômica no XII Enanpege (2017)
}

State of the art of economic geography in the XII Enanpege (2017)

Estado del arte de la geografía económica en el XII Enanpege (2017)

Etat de l'art de la géographie économique au XII Enanpege (2017)

\section{Izabelle de Oliveira Felez}

\section{OpenEdition}

Journals

\section{Edição electrónica}

URL: http://journals.openedition.org/espacoeconomia/9114

DOI: 10.4000/espacoeconomia.9114

ISSN: 2317-7837

\section{Editora}

Núcleo de Pesquisa Espaço \& Economia

\section{Refêrencia eletrónica}

Izabelle de Oliveira Felez, «Estado da arte da geografia econômica no XII Enanpege (2017) », Espaço e Economia [Online], 16 | 2019, posto online no dia 01 janeiro 2020, consultado o 10 janeiro 2020. URL : http://journals.openedition.org/espacoeconomia/9114; DOI : 10.4000/espacoeconomia.9114

Este documento foi criado de forma automática no dia 10 janeiro 2020.

(C) NUPEE 


\title{
Estado da arte da geografia econômica no XII Enanpege (2017)
}

\author{
State of the art of economic geography in the XII Enanpege (2017) \\ Estado del arte de la geografía económica en el XII Enanpege (2017) \\ Etat de l'art de la géographie économique au XII Enanpege (2017)
}

Izabelle de Oliveira Felez

\section{INTRODUÇÃO}

1 Nesta investigação serão apresentados dados sobre os grupos de trabalhos (GTs), no qual a temática do Desenvolvimento Regional e Infraestrutura se coloca necessária pelas características atuais do processo de desenvolvimento brasileiro, pautado: no fortalecimento da intervenção do Estado; retomada da elaboração de políticas públicas e dos investimentos em infraestruturas; novos modelos regulatórios para a concessão dos serviços públicos; atuação das corporações e seu papel na internacionalização da produção. São temas pertinentes à discussão sobre o desenvolvimento regional brasileiro, suas repercussões, conflitos de interesses, embate capital x trabalho e o papel do Brasil na divisão internacional do trabalho. Este Grupo de Trabalho tem origem na discussão acumulada pelo Grupo de Estudos em Desenvolvimento Regional e Infraestruturas (GEDRI), em funcionamento desde o ano de 2005, do Grupo de Estudos da Dinâmica Econômica, desde 2008 e do Núcleo de Pesquisa Espaço e Economia (NUPEE), desde 2008.

2 O GT tem por seu objetivo de aglutinar 5 eixos de pesquisa: 1) Circulação, transportes e logística; 2) Financeirização do território nacional e internacionalização da economia brasileira; 3) Políticas públicas e desenvolvimento regional; 4) Desenvolvimento econômico, política industrial e comércio exterior; 5) Agronegócio e circuitos espaciais da produção 
3 Tem-se como meta a criação de espaços de discussão que permita a socialização das experiências de pesquisa, reunião de um acervo qualificado com desdobramentos para a qualificação da pós-graduação e efetiva contribuição ao debate nacional.

4 No segundo GT Formações Socioespaciais: Progresso técnico no espaço Urbano e Agrário, aqui apontamos que a crise da economia mundial, iniciada em 1973, trouxe para o debate acadêmico as questões referentes à inovação tecnológica (biotecnologia, telecomunicações, robótica, entre outras) como possibilidade de retomada do crescimento econômico. Contudo, a formação socioespacial estadunidense com sua política de liberalização do comércio internacional, oligopolização da economia, financeirização e políticas neoliberais, sobretudo, para fora, retardou o processo de destruição criativa e impôs diferentes estratégias às variadas formações socioespaciais do centro e da periferia do sistema capitalista. As análises aqui pretendidas direcionamse para o agrário e o urbano. Nesse sentido, na formação socioespacial brasileira, se questiona: quais as dinâmicas capitalistas que presidem a formação e expansão de aglomerações urbanas e continuidade do processo de metropolização?

5 Do ponto de vista agrário, o centro da discussão se dá em relação à produção agroalimentar, sua inserção em cadeias mais amplas, ao financiamento da produção e à financeirização cada vez mais presente na agricultura. Assim, esse GT tem por objetivo discutir o impacto dessas políticas e do progresso técnico no desenvolvimento econômico mundial / nacional / regional / local vinculado às atividades agrárias e urbanas.

\section{Importância do Estado da Arte para a Pesquisa da Geografia Econômica}

6 A Geografia Econômica surgiu como uma vertente para estudar as transformações espaciais promovidas pelas relações econômicas. Sua abordagem esclarece os fatores responsáveis pela condição econômica de um determinado local, enfatizando os elementos propícios para a instalação das indústrias (clima, disponibilidade de recursos naturais, relações políticas, mercado consumidor, etc.) e as consequências espaciais desse processo.

7 A origem da Geografia Econômica e, assim, sua evolução teórico-metodológica é marcada por vários paradigmas e contextos econômico-sociais que originam mudanças e reconfigurações. A partir de 1950, transformações originadas de situações internas à disciplina (debates sobre método, modelo); e conjunturas externas - a relação com outras disciplinas (sobretudo, a Economia) e a realidade socioeconômica que motivavam debates, influenciou as abordagens e os temas.

8 A Geografia Econômica se consolida no início do século XX pelo acúmulo de informações econômicas de países e cidades, das condições físicas, dos recursos naturais; pelo desenvolvimento das monografias de agricultura; dos relatórios comerciais feitos pelas casas de negócios; e pelos fundamentos da Geografia Humana. Baseou-se nos aspectos da disciplina econômica; na concepção do homem como ser econômico; e na influência homem-meio.

O estado da arte baseia-se no mapeamento (uma pesquisa) que possibilitará o conhecimento e/ou reconhecimento de estudos que estão sendo, ou já foram realizados no Brasil (em alguns casos no mundo) com temáticas, ou linhas de pesquisa, iguais ou 
parecidas em que está se estudando. Geralmente, a pesquisa é realizada apenas dentro de sua área de estudo, pois além de reconhecer o que está, ou foi investigado, você poderá usar posteriormente os materiais encontrados para sua revisão de literatura, no qual este trabalho refere-se a um levantamento, do tipo "estado da arte", das pesquisas publicadas nos anais do XII Encontro Nacional da Associação Nacional de Pós-graduação e Pesquisa em Geografia (ENANPEGE). Especificamente, buscaram-se analisar os estudos dos GTs já citados. Por meio deste estudo, procurou-se elaborar um panorama quantitativo e qualitativo a respeito das pesquisas que vêm sendo realizadas nesse eixo, em termos de temáticas.

10 Com base nessas informações de caráter descritivo, almeja-se também analisar em que medida tais pesquisas têm dialogado com as questões educacionais mais emergentes em nosso país, propondo temas relevantes nesse sentido. Segundo Ferreira (2002), os estudos relativos ao "estado da arte" podem ser definidos como uma modalidade de pesquisa bibliográfica, que têm por objetivo:

o desafio de mapear e de discutir uma certa produção acadêmica em diferentes campos do conhecimento, tentando responder que aspectos e dimensões vêm sendo destacados e privilegiados em diferentes épocas e lugares, de que formas e em que condições têm sido produzidas certas dissertações de mestrado, teses de doutorado, publicações em periódicos e comunicações em anais de congressos e de seminários. (FERREIRA, 2002, p. 258).

11 As pesquisas do tipo "estado da arte" sobre as produções de uma determinada área ou instituição são uma possibilidade de verificar-se a situação do conhecimento em um dado momento, permitindo colocar em ordem as diversas informações, além de compreender as relações existentes entre elas, em termos de semelhanças e contradições. Portanto podem surgir diversas possibilidades de análises a partir desse olhar panorâmico para um conjunto de produções.

estado da arte também é conhecido por sua notoriedade em realizar um método cujas características se mostrem como algo inventariante e descritivo em relação à produção acadêmica e científica acerca do tema que procura pesquisar, "[...] à luz de categorias e facetas que se caracterizam enquanto tais em cada trabalho e no conjunto deles, sob os quais o fenômeno passa a ser analisado". (FERREIRA, 2002, p. 258).

13 O estado da arte refere-se a uma atividade árdua e complexa, justamente por seu caráter crítico e reflexivo. Auxilia na otimização e também no desenvolvimento de novas demandas de pesquisa, conceitos e paradigmas.

Haddad (2002, p. 09) conceitua o estado da arte como sendo os estudos que:

[...] permitem, num recorte temporal definido, sistematizar um determinado campo de conhecimento, reconhecer os principais resultados da investigação, identificar temáticas a abordagens dominantes e emergentes, bem como lacunas e campos inexplorados abertos a pesquisas futuras.

15 Um dos objetivos principais deste tipo de pesquisa é buscar compreender o conhecimento que existe sobre algum tema, a partir de um recorte temporal específico, além de sua sistematização e análise acerca do assunto, que não somente resgata como também condensa a produção acadêmica num campo específico. 


\section{ANÁLISE DOS TRABALHOS DE GEOGRAFIA ECONÔMICA}

Ressaltamos que foram 56 trabalhos publicados nos anais, onde os mesmos foram apresentados e debatidos e os quais serão o foco de análise do nosso estado da arte. Os elementos presentes no quadro 1 representam a cartografia das pesquisas baseadas na temática do Desenvolvimento Regional e Infraestrutura. As vinte e oito pesquisas apresentadas e sabatinadas foram classificadas em cinco eixos: 1) Circulação, transportes e logística; 2) Financeirização do território nacional; 3) Políticas públicas e desenvolvimento regional; 4) Desenvolvimento econômico, política industrial e comércio exterior; 5) Agronegócio e circuitos espaciais da produção. Já os demais vinte e oito trabalhos presentes no GT "Formações Socioespaciais: progresso técnico no espaço urbano e agrário" não foram divididos em eixos temáticos - quadro 2.

A análise quantitativa dos dois GTs se deu através das regiões e universidades com 2 ou mais estudos apresentados no evento, no qual a figura 1 faz essa representatividade.

Figura 1- Análise quantitativa dos GTs de geografia econômica do ENANPEGE 2017
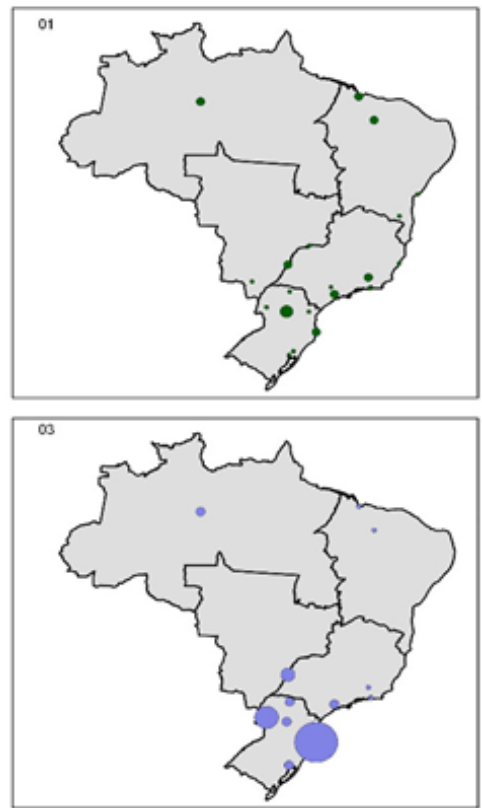

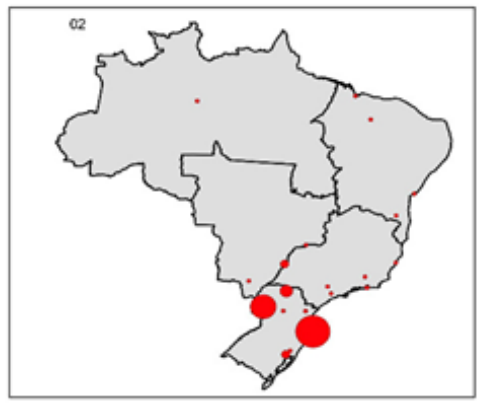

Análise quantitativa dos GT's de geografia econômica do ENANPEGE 2017

Número de trabalhos apresentados por Universidade

$\begin{array}{ll}\text { GT DESEN. } & \text { GT FORMACOES TOTAL } \\ \text { REGIONALE } & \text { SOCIOESPACIAIS }\end{array}$ REGIONALE SOCIOESPACIAIS * 1 Trabalho INFRAESTRUTURA * 1 Trabalho - 3 Trabalhos

- 1 Trabalho 3 Trabalhos 5 Trabalhos

- 2 Trabalhos 5 Trabalhos

- 3 Trabalhos

7 Trabalhos

8 Trabalhos
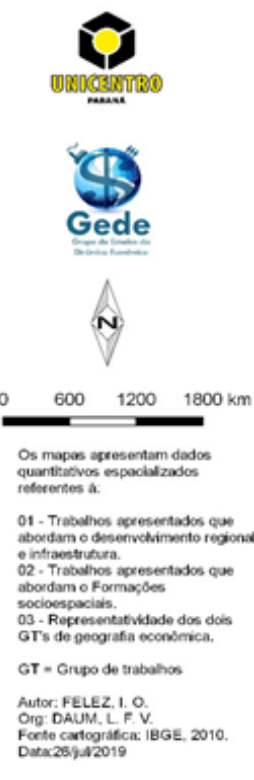

Quadro 1 - Síntese dos trabalhos apresentados no Grupo de Trabalho "Desenvolvimento Regional e Infraestrutura" do XII Encontro Nacional da Associação Nacional de Pós-graduação e Pesquisa em Geografia (ENANPEGE) - Porto Alegre (RS)- 2017.

\begin{tabular}{|l|l|l|l|l|l|}
\hline Título & Eixos de Pesquisa & Instituição & $\begin{array}{l}\text { Cidade/ } \\
\text { Estado/ } \\
\text { Região }\end{array}$ & $\begin{array}{l}\text { Nível da } \\
\text { pesquisa }\end{array}$ & Palavras-chaves \\
\hline
\end{tabular}




\begin{tabular}{|c|c|c|c|c|c|}
\hline $\begin{array}{l}\text { 1.Novos } \\
\text { "territórios } \\
\text { eólicos: } \\
\text { apropriações e } \\
\text { conflitos. }\end{array}$ & $\begin{array}{lr}\text { 2) } & \text { Financeirização } \\
\text { do } & \text { território } \\
\text { nacional } & \text { e } \\
\text { internacionalização } \\
\text { da } & \text { economia } \\
\text { brasileira; }\end{array}$ & UFS & $\begin{array}{l}\text { São Cristóvão } \\
\text { /SE/NE }\end{array}$ & $\begin{array}{l}\text { Doutorado } \\
\text { em } \\
\text { andamento }\end{array}$ & $\begin{array}{l}\text { Território; } \\
\text { Território -rede; } \\
\text { Parques eólicos. }\end{array}$ \\
\hline $\begin{array}{l}\text { 2. A Evolução das } \\
\text { políticas federais } \\
\text { de transporte } \\
\text { público: difusão } \\
\text { do Sistema brt } \\
\text { bus Rapid transit } \\
\text { em Cidades } \\
\text { brasileiras. }\end{array}$ & $\begin{array}{l}\text { 1) Circulação, } \\
\text { transportes } \\
\text { logística; }\end{array}$ & UFF & Niterói/RJ/SE & $\begin{array}{l}\text { Mestrado } \\
\text { concluído }\end{array}$ & $\begin{array}{l}\text { Políticas de } \\
\text { transporte; } \\
\text { urbano; BRT. }\end{array}$ \\
\hline $\begin{array}{l}\text { 3. A Ferrovia } \\
\text { nova } \\
\text { transnordestina } \\
\text { e os novos } \\
\text { trilhos da fluidez } \\
\text { Territorial no } \\
\text { Piauí. }\end{array}$ & $\begin{array}{l}\text { 1) Circulação, } \\
\text { transportes e } \\
\text { logística; }\end{array}$ & UFPI & $\begin{array}{l}\text { Teresina/PI/ } \\
\text { NE }\end{array}$ & $\begin{array}{l}\text { Mestrado } \\
\text { concluído }\end{array}$ & $\begin{array}{l}\text { Transportes; } \\
\text { Território; } \\
\text { Ferrovia Nova } \\
\text { Transnordestina }\end{array}$ \\
\hline $\begin{array}{l}\text { 4. A Globalização } \\
\text { da produção e as } \\
\text { empresas } \\
\text { estrangeiras: um } \\
\text { debate } \\
\text { Geoeconômico. }\end{array}$ & $\begin{array}{l}\text { 4) } \\
\text { Desenvolvimento } \\
\text { econômico, política } \\
\text { industrial } \\
\text { comércio exterior; }\end{array}$ & UNICENTRO & $\begin{array}{l}\text { Guarapuava/ } \\
\mathrm{PR} / \mathrm{S}\end{array}$ & $\begin{array}{l}\text { Mestrado } \\
\text { concluído }\end{array}$ & $\begin{array}{l}\text { Globalização; } \\
\text { internacionalizaçã } \\
\text { empresas } \\
\text { estrangeiras }\end{array}$ \\
\hline $\begin{array}{l}\text { 5. A Importância } \\
\text { das redes viárias } \\
\text { na dinâmica } \\
\text { socioeconômica } \\
\text { da } \\
\text { Microrregião de } \\
\text { vitória da } \\
\text { Conquista BA. }\end{array}$ & $\begin{array}{l}\text { 3) Políticas } \\
\text { públicas } \\
\text { desenvolvimento } \\
\text { regional; }\end{array}$ & UESB & $\begin{array}{l}\text { Itapetinga/ } \\
\mathrm{BA} / \mathrm{NE}\end{array}$ & $\begin{array}{l}\text { Mestrado } \\
\text { em } \\
\text { andamento }\end{array}$ & $\begin{array}{l}\text { Redes; Redes } \\
\text { viárias; } \\
\text { Microrregião }\end{array}$ \\
\hline $\begin{array}{l}\text { 6. A Integração } \\
\text { territorial nos } \\
\text { blocos regionais: } \\
\text { uma abordagem } \\
\text { das } \\
\text { Políticas } \\
\text { setoriais de } \\
\text { transporte. }\end{array}$ & $\begin{array}{l}\text { 3) Políticas } \\
\text { públicas } \\
\text { desenvolvimento } \\
\text { regional; }\end{array}$ & UFSC & $\begin{array}{l}\text { Florianópolis/ } \\
\mathrm{SC} / \mathrm{S}\end{array}$ & \begin{tabular}{|l} 
Doutorado \\
em \\
andamento
\end{tabular} & $\begin{array}{l}\text { Integração } \\
\text { territorial, } \\
\text { integração } \\
\text { regional, } \\
\text { transportes. }\end{array}$ \\
\hline
\end{tabular}




\begin{tabular}{|c|c|c|c|c|c|}
\hline $\begin{array}{l}\text { 7. Análise Da } \\
\text { dinâmica do } \\
\text { setor de serviços } \\
\text { em áreas } \\
\text { litorâneas: um } \\
\text { Estudo de caso } \\
\text { dos municípios } \\
\text { de cajueiro da } \\
\text { praia e Luiz } \\
\text { Correia no Piauí. }\end{array}$ & $\begin{array}{lr}\text { 2) } & \text { Financeirização } \\
\text { do } & \text { território } \\
\text { nacional } & \text { e } \\
\text { internacionalização } \\
\text { da } & \text { economia } \\
\text { brasileira; }\end{array}$ & UFPI & $\begin{array}{l}\text { Teresina/PI/ } \\
\mathrm{NE}\end{array}$ & $\begin{array}{l}\text { Mestrado } \\
\text { em } \\
\text { andamento }\end{array}$ & $\begin{array}{l}\text { Turismo; Litoral; } \\
\text { Infraestrutura. }\end{array}$ \\
\hline $\begin{array}{lr}8 . & \text { Cervejas } \\
\text { Especiais: análise } \\
\text { do circuito } \\
\text { espacial da } \\
\text { produção e dos } \\
\text { Círculos de } \\
\text { cooperação do } \\
\text { espaço das } \\
\text { microcervejarias } \\
\text { paulistas. }\end{array}$ & $\begin{array}{l}\text { 5) Reestruturação } \\
\text { produtiva } \\
\text { industrialização. }\end{array}$ & UNESP & $\begin{array}{ll}\text { São } & \text { Paulo/ } \\
\text { SP/SE } & \end{array}$ & $\begin{array}{l}\text { Mestrado } \\
\text { em } \\
\text { andamento }\end{array}$ & $\begin{array}{lr} & \\
\text { Circuito } & \text { Espacial } \\
\text { da } & \text { Produção; } \\
\text { Círculos } & \text { de } \\
\text { Cooperação } & \text { no } \\
\text { Espaço; } & \\
\text { Microcervejarias. }\end{array}$ \\
\hline $\begin{array}{lr}9 . & \text { Circuito } \\
\text { Espacial de } \\
\text { produção de } \\
\text { jeans } \\
\text { Cianorte/PR: } \\
\text { Reestruturação e } \\
\text { fragmentação } \\
\text { produtiva. }\end{array}$ & $\begin{array}{l}\text { 5) Reestruturação } \\
\text { produtiva } \\
\text { industrialização. }\end{array}$ & UNICENTRO & $\begin{array}{l}\text { Guarapuava/ } \\
\mathrm{PR} / \mathrm{S}\end{array}$ & $\begin{array}{l}\text { Mestrado } \\
\text { concluído }\end{array}$ & $\begin{array}{ll}\text { Produção } & \text { de } \\
\text { jeans; lógicas de } & \text { acumulação; } \\
\text { lavanderias } & \\
\text { industriais. } & \end{array}$ \\
\hline $\begin{array}{l}\text { 10. De Cidade } \\
\text { litorânea } \\
\text { cidade portuária: } \\
\text { novas } \\
\text { configurações } \\
\text { Socioespaciais e } \\
\text { migração no } \\
\text { litoral norte de } \\
\text { São Paulo. }\end{array}$ & $\begin{array}{l}\text { 4) } \\
\text { Desenvolvimento } \\
\text { econômico, política } \\
\text { industrial } \\
\text { comércio exterior; }\end{array}$ & UNICAMP & $\begin{array}{l}\text { Campinas/ } \\
\mathrm{SP} / \mathrm{SE}\end{array}$ & $\begin{array}{l}\text { Mestrado } \\
\text { em } \\
\text { andamento }\end{array}$ & $\begin{array}{l}\text { Urbanização, } \\
\text { Migração } \\
\text { internacional; } \\
\text { Litoral Norte de } \\
\text { São Paulo }\end{array}$ \\
\hline $\begin{array}{lr}\text { 11. De Subúrbio } \\
\text { industrial } \\
\text { cidade } \\
\text { serviços: } \\
\text { Gonçalo e } \\
\text { Tendências } \\
\text { atuais } \\
\text { urbanização } \\
\text { periferia } \\
\text { fluminense. } \\
\end{array}$ & $\begin{array}{l}\text { 3) Políticas } \\
\text { públicas } \\
\text { desenvolvimento } \\
\text { regional; }\end{array}$ & USP & $\begin{array}{ll}\text { São } & \text { Paulo/ } \\
\text { SP/SE } & \end{array}$ & $\begin{array}{l}\text { Doutorado } \\
\text { em } \\
\text { andamento }\end{array}$ & $\begin{array}{l}\text { Função industrial } \\
\text { - São Gonçalo - } \\
\text { Economia urbana }\end{array}$ \\
\hline
\end{tabular}




\begin{tabular}{|c|c|c|c|c|c|}
\hline $\begin{array}{l}\text { 12. Dinâmica } \\
\text { Econômica e o } \\
\text { setor portuário } \\
\text { de Sergipe: } \\
\text { fluxos de } \\
\text { Mercadorias e } \\
\text { estratégias } \\
\text { competitivas. }\end{array}$ & $\begin{array}{l}\text { 1) Circulação, } \\
\text { transportes } \\
\text { logística; }\end{array}$ & UFS & $\begin{array}{l}\text { São Cristóvão } \\
\text { /SE/NE }\end{array}$ & Docente & $\begin{array}{l}\text { Setor portuário, } \\
\text { mercadorias, } \\
\text { estratégias } \\
\text { competitivas. }\end{array}$ \\
\hline 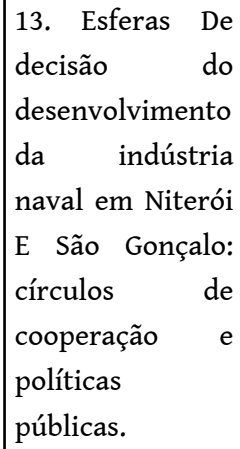 & $\begin{array}{l}\text { 3) Políticas } \\
\text { públicas } \\
\text { desenvolvimento } \\
\text { regional; }\end{array}$ & UFRJ & $\begin{array}{l}\text { Rio de Janeiro } \\
\text { /RJ/SE }\end{array}$ & $\begin{array}{l}\text { Mestrado } \\
\text { concluído }\end{array}$ & $\begin{array}{l}\text { Indústria naval; } \\
\text { petróleo; círculos } \\
\text { de cooperação. }\end{array}$ \\
\hline $\begin{array}{l}\text { 14. Estratégias } \\
\text { Dos agentes } \\
\text { econômicos } \\
\text { varejistas no } \\
\text { território } \\
\text { Brasileiro no } \\
\text { início do século } \\
\text { XXI. }\end{array}$ & $\begin{array}{l}\text { 5) Reestruturação } \\
\text { produtiva } \\
\text { industrialização. }\end{array}$ & UFRGS & $\begin{array}{l}\text { Rio grande/ } \\
\text { RS/S }\end{array}$ & $\begin{array}{l}\text { Mestrado } \\
\text { em } \\
\text { andamento }\end{array}$ & $\begin{array}{ll}\text { Varejo; } & \text { segunda } \\
\text { palavra; } & \text { terceira } \\
\text { palavra } & \end{array}$ \\
\hline $\begin{array}{l}15 . \quad \text { Goma } \\
\text { Artesanal versus } \\
\text { fécula industrial: } \\
\text { substituição no } \\
\text { consumo Em } \\
\text { Manacapuru AM. }\end{array}$ & $\begin{array}{l}\text { 3) Políticas } \\
\text { públicas e } \\
\text { desenvolvimento } \\
\text { regional; }\end{array}$ & UFAM & $\begin{array}{l}\text { Manaus/AM/ } \\
\mathrm{N}\end{array}$ & Docente & $\begin{array}{l}\text { Fécula, } \\
\text { Manacapuru, } \\
\text { políticas de } \\
\text { desenvolvimento. }\end{array}$ \\
\hline $\begin{array}{l}\text { 16. Impactos Da } \\
\text { geração de } \\
\text { energia eólica no } \\
\text { município de } \\
\text { Marcolândia, } \\
\text { Estado do Piauí, } \\
\text { brasil. }\end{array}$ & $\begin{array}{l}\text { 5) Reestruturação } \\
\text { produtiva e } \\
\text { industrialização. }\end{array}$ & UFES & Vitória/ES/SE & $\begin{array}{l}\text { Mestrado } \\
\text { em } \\
\text { andamento }\end{array}$ & $\begin{array}{l}\text { Sustentabilidade; } \\
\text { Fontes } \\
\text { renováveis; } \\
\text { Energia Eólica. }\end{array}$ \\
\hline $\begin{array}{l}\text { 17. Instituições } \\
\text { Públicas de } \\
\text { ensino superior } \\
\text { no estado do } \\
\text { Paraná e o } \\
\text { Desenvolvimento } \\
\text { local e regional. }\end{array}$ & \begin{tabular}{|lr}
$2)$ & Financeirização \\
do & território \\
nacional & e \\
internacionalização \\
da & economia \\
brasileira;
\end{tabular} & UFPR & Curitiba/PR/S & $\begin{array}{l}\text { Doutorado } \\
\text { em } \\
\text { andamento }\end{array}$ & $\begin{array}{l}\text { Desenvolvimento } \\
\text { Local e Regional; } \\
\text { Ensino Superior; } \\
\text { Territorialização }\end{array}$ \\
\hline
\end{tabular}




\begin{tabular}{|c|c|c|c|c|c|}
\hline $\begin{array}{l}18 . \text { Logística } \\
\text { Como } \\
\text { instrumento de } \\
\text { articulação entre } \\
\text { os espaços da } \\
\text { Produção e do } \\
\text { consumo: o caso } \\
\text { do setor } \\
\text { sucroenergético } \\
\text { no Triângulo } \\
\text { mineiro. }\end{array}$ & $\begin{array}{lr}\text { 2) } & \text { Financeirização } \\
\text { do } & \text { território } \\
\text { nacional } & \text { e } \\
\text { internacionalização } \\
\text { da } & \text { economia } \\
\text { brasileira; }\end{array}$ & UFJF & $\begin{array}{l}\text { Juiz de Fora/ } \\
\mathrm{MG} / \mathrm{CO}\end{array}$ & Docente & $\begin{array}{l}\text { Logística; setor } \\
\text { sucroenergético; } \\
\text { Triângulo } \\
\text { Mineiro. }\end{array}$ \\
\hline $\begin{array}{l}\text { 19. O Aeroporto } \\
\text { internacional de } \\
\text { São Paulo / } \\
\text { Guarulhos como } \\
\text { Centralidade } \\
\text { urbana e a } \\
\text { logística } \\
\text { comercial } \\
\text { aeroportuária. }\end{array}$ & $\begin{array}{lr}\text { 2) } & \text { Financeirização } \\
\text { do } & \text { território } \\
\text { nacional } & \text { e } \\
\text { internacionalização } \\
\text { da } & \text { economia } \\
\text { brasileira; }\end{array}$ & USP & $\begin{array}{ll}\text { São } & \text { Paulo/ } \\
\text { SP/SE } & \end{array}$ & $\begin{array}{l}\text { Mestrado } \\
\text { concluído }\end{array}$ & $\begin{array}{l}\text { Centralidade, } \\
\text { Aeroporto, } \\
\text { logística }\end{array}$ \\
\hline $\begin{array}{l}20 . \\
\text { Desenvolvimento } \\
\text { da região do } \\
\text { pontal do } \\
\text { Paranapanema } \\
\text { no contexto } \\
\text { Da } \\
\text { reestruturação } \\
\text { produtiva do } \\
\text { capital. }\end{array}$ & $\begin{array}{l}\text { 4) } \\
\text { Desenvolvimento } \\
\text { econômico, política } \\
\text { industrial e } \\
\text { comércio exterior; }\end{array}$ & UNESP & $\begin{array}{ll}\text { São } & \text { Paulo/ } \\
\text { SP/SE } & \end{array}$ & $\begin{array}{l}\text { Doutorado } \\
\text { em } \\
\text { andamento }\end{array}$ & $\begin{array}{l}\text { Desenvolvimento; } \\
\text { Reestruturação } \\
\text { produtiva; } \\
\text { Sucroenergético. }\end{array}$ \\
\hline $\begin{array}{ll}\text { 21. O Setor de } \\
\text { vestuário no } \\
\text { Mato Grosso do } \\
\text { Sul. }\end{array}$ & $\begin{array}{l}\text { 5) Reestruturação } \\
\text { produtiva e } \\
\text { industrialização. }\end{array}$ & UFGD & $\begin{array}{l}\text { Dourados/ } \\
\text { MS/CO }\end{array}$ & $\begin{array}{l}\text { Doutorado } \\
\text { em } \\
\text { andamento }\end{array}$ & $\begin{array}{l}\text { Vestuário; } \\
\text { Industrialização; } \\
\text { Geração de } \\
\text { empregos. }\end{array}$ \\
\hline $\begin{array}{lr}22 . & 0 \\
\text { Taylorismo/ } & \\
\text { Fordismo } & \text { no } \\
\text { Brasil: } & \text { a } \\
\text { ocupação } & \text { do } \\
\text { capital no espaço } \\
\text { Fabril. }\end{array}$ & $\begin{array}{l}\text { 4) } \\
\text { Desenvolvimento } \\
\text { econômico, política } \\
\text { industrial } \\
\text { comércio exterior; }\end{array}$ & UFJF & $\begin{array}{l}\text { Juiz de Fora/ } \\
\text { MG/CO }\end{array}$ & $\begin{array}{l}\text { Mestrado } \\
\text { em } \\
\text { andamento }\end{array}$ & $\begin{array}{l}\text { Economia; } \\
\text { Fordismo; } \\
\text { História } \\
\text { Econômica; } \\
\text { Industrialização; } \\
\text { Taylorismo }\end{array}$ \\
\hline
\end{tabular}




\begin{tabular}{|c|c|c|c|c|c|}
\hline $\begin{array}{l}\text { 23. Os Reflexos } \\
\text { das concessões } \\
\text { aeroportuárias } \\
\text { no r Brasil: } \\
\begin{array}{lr}\text { avanços } & \text { e } \\
\text { Retrocessos. }\end{array}\end{array}$ & $\begin{array}{l}\text { 1) Circulação, } \\
\text { transportes } \\
\text { logística; }\end{array}$ & UFSC & $\begin{array}{l}\text { Florianópolis/ } \\
\mathrm{SC} / \mathrm{S}\end{array}$ & $\begin{array}{l}\text { Doutorado } \\
\text { em } \\
\text { andamento }\end{array}$ & $\begin{array}{l}\text { Concessões } \\
\text { aeroportuárias; } \\
\text { transporte aéreo; } \\
\text { aeroportos. }\end{array}$ \\
\hline $\begin{array}{l}\text { 24. Planejamento } \\
\text { E } \\
\text { desenvolvimento } \\
\text { regional no } \\
\text { estado ro } \\
\text { Tocantins: Uma } \\
\text { leitura a partir } \\
\text { dos planos de } \\
\text { desenvolvimento } \\
\text { e } \\
\text { significados Para } \\
\text { região Norte do } \\
\text { Estado. }\end{array}$ & $\begin{array}{l}\text { 3) Políticas } \\
\text { públicas } \\
\text { desenvolvimento } \\
\text { regional; }\end{array}$ & IFMA & $\begin{array}{l}\text { São Luis / } \\
\text { MA/NE }\end{array}$ & $\begin{array}{l}\text { Mestrado } \\
\text { concluído }\end{array}$ & $\begin{array}{l}\text { Desenvolvimento } \\
\text { regional; Planos } \\
\text { de } \\
\text { desenvolvimento } \\
\text { regional; } \\
\text { Tocantins. }\end{array}$ \\
\hline $\begin{array}{l}\text { 25. Profesor De } \\
\text { ciências sociales } \\
\text { en el grado de } \\
\text { licenciatura. }\end{array}$ & $\begin{array}{l}\text { 3) Políticas } \\
\text { públicas } \\
\text { desenvolvimento } \\
\text { regional; }\end{array}$ & UFAM & $\begin{array}{l}\text { Manaus/AM/ } \\
\mathrm{N}\end{array}$ & $\begin{array}{l}\text { Graduação } \\
\text { concluída }\end{array}$ & $\begin{array}{l}\text { Informalidad, } \\
\text { Trabajo Humano, } \\
\text { Competencia }\end{array}$ \\
\hline $\begin{array}{l}26 . \\
\text { Reestruturação } \\
\text { Econômica e } \\
\text { regional no rio } \\
\text { de Janeiro: uma } \\
\text { análise Sobre a } \\
\text { região dos lagos. }\end{array}$ & $\begin{array}{l}\text { 3) Políticas } \\
\text { públicas } \\
\text { desenvolvimento } \\
\text { regional; }\end{array}$ & UERJ & $\begin{array}{l}\text { Rio de Janeiro } \\
\text { /RJ/SE }\end{array}$ & $\begin{array}{l}\text { Mestrado } \\
\text { concluído }\end{array}$ & $\begin{array}{l}\text { Turismo, estadia } \\
\text { temporária, } \\
\text { região. }\end{array}$ \\
\hline $\begin{array}{l}27 . \\
\text { Reestruturação } \\
\text { Produtiva e } \\
\text { indústria: capital } \\
\text { e formação da } \\
\text { força De trabalho } \\
\text { para a produção } \\
\text { de alimentos de } \\
\text { vitória da } \\
\text { conquista BA. }\end{array}$ & $\begin{array}{l}\text { 4) } \\
\text { Desenvolvimento } \\
\text { econômico, política } \\
\text { industrial } \\
\text { comércio exterior; }\end{array}$ & UFS & $\begin{array}{l}\text { São } \\
\text { Cristóvão/ } \\
\text { SE/NE }\end{array}$ & $\begin{array}{l}\text { Mestrado } \\
\text { concluído }\end{array}$ & $\begin{array}{l}\text { Capital; } \\
\text { Reestruturação } \\
\text { Produtiva; Força } \\
\text { de Trabalho }\end{array}$ \\
\hline $\begin{array}{lr}28 . & \text { A } \\
\text { Espacialização } \\
\text { dos bancos } \\
\text { públicos e o } \\
\text { desenvolvimento } \\
\text { regional. }\end{array}$ & $\begin{array}{l}\text { 3) Políticas } \\
\text { públicas } \\
\text { desenvolvimento } \\
\text { regional; }\end{array}$ & UNICENTRO & $\begin{array}{l}\text { Guarapuava/ } \\
\mathrm{PR} / \mathrm{S}\end{array}$ & $\begin{array}{l}\text { Mestrado } \\
\text { concluído }\end{array}$ & $\begin{array}{l}\text { Sistema bancário; } \\
\text { bancos públicos; } \\
\text { rede de agências }\end{array}$ \\
\hline
\end{tabular}


FONTE: Anais do XII Encontro Nacional da ANPEGE, 2017. ORg. Autores.

- Docentes: 3 pesquisas;

Continuando a análise do quadro 1 e mapa 1, observamos que, numa divisão regional foram apresentados trabalhos oriundos das seguintes regiões: Sudeste (9), Sul (7), Centro-Oeste (3), Norte (2) e Nordeste (7).

Em relação ao nível da pesquisa, temos a seguinte radiografia:

- Doutorado em andamento: 7 pesquisas;

- Mestrado concluído: 10 trabalhos;

- Mestrado em andamento: 7 estudos;

- Graduação concluída: 1 pesquisa.

Portanto, os dois níveis de pesquisa com maior representação no GT são: Mestrado em andamento, com 7 trabalhos (25\%); e Mestrado concluído: 10 trabalhos (35,7\%); totalizando 17 pesquisas $(60,7 \%)$ do total de 28 .

As Universidades representadas no GT com 2 ou mais estudos (as demais tiveram apenas um trabalho apresentado), por ordem decrescente do número de pesquisas são:

1. Universidade Federal de Sergipe: 3;

2. Universidade do Centro - Oeste do Paraná: 3;

3. Universidade Federal do Piauí: 2;

4. Universidade Federal de Santa Catarina: 2;

5. Universidade Estadual Paulista: 2;

6. Universidade de São Paulo: 2;

7. Universidade Federal do Amazonas: 2;

8. Universidade Federal de Juiz de Fora: 2.

Começaremos a análise qualitativa pelo eixo 1 "Circulação, transportes e logística". Estas pesquisas versaram primordialmente sobre: o deslocamento de pessoas e produtos, no qual foi uma necessidade desde as primeiras formas de organização humana. Ao longo do tempo, de acordo com a necessidade e os materiais disponíveis em seu meio, o homem desenvolveu diversas formas de deslocamento e circulação.

Desta forma, existem diversos meios, assim como infraestruturas de transportes que evoluíram, revolucionando a circulação. Quando tratamos tradicionalmente da geografia da circulação e da geografia dos transportes deixamos de lado parte importante da cadeia de abastecimento, ou seja, o armazenamento na distribuição (logística de distribuição). Esse fato deve-se ao momento histórico que essas subáreas da geografia são formuladas. Por mais que as atividades de transporte e armazenamento tenham utilizado alguma forma de logística (estratégia, planejamento e gestão de transportes e armazenamento) foi especialmente na década de 1980 que a discussão sobre planejamento e gestão interligados de transporte, de armazenamento e seus impactos territoriais foi discutido globalmente com intensidade.

Nos trabalhos destacam-se:

- A questão do capitalismo, marcado pela necessidade da progressiva aceleração da circulação. Os transportes se evidenciam como elemento crucial para a reprodução das atividades econômicas e das relações sociais em geral. As transformações na circulação de pessoas e 
mercadorias nos territórios, em sua fluidez, conferem importância destacada aos transportes, tendo assim papel destacado na difusão e consolidação da sociedade moderna;

- Difusão do sistema de transporte urbano BRT - Bus Rapid Transit, em cidades brasileiras, problematizando-a no âmbito das políticas Municipal e Federal de mobilidade urbana. Para isso, é contextualizado como as políticas de transporte urbano foram inseridas nos planos diretores municipais. Constatou-se através das análises que, os planos de transportes urbanos não acompanharam as transformações ocorridas no Brasil a partir de 1960, como a industrialização, a intensificação da urbanização, ampliação e densificação da rede urbana;

- A modernização e a expansão territorial dos transportes, comunicação e informática têm possibilitado nos dias atuais, uma inserção de lugares e espaços no contexto mundial. A circulação de mercadorias e pessoas tornam-se cada vez mais intensas na escala regional, nacional e internacional. Os interesses e as estratégias dos capitalistas avançam e se expandem na mesma proporção, configurando e reconfigurando os espaços locais e globais. Existe uma relação estreita entre o desenvolvimento das cidades e os meios de transportes, tornando-se elementos indissociáveis para a estruturação urbana.

A respeito dos demais eixos optamos por analisarmos juntos nos quais a seguir apontaremos os principais destaques dos mesmos:

- Uma vez que o comércio intrarregional apresentou resultados cada vez mais favoráveis, os blocos regionais elaboraram políticas de cooperação em diversos setores. Foi o caso das políticas de transporte transnacionais, as quais conquistaram maior atenção no final do século XX. No decorrer das últimas décadas houve muitos debates acerca da necessidade de fomentar a integração territorial regional, porém quase sempre de maneira bilateral entre os países, decorrendo na realização de obras de maneira pontual. Já com o estabelecimento de organismos de integração regional essa pauta passou a ser abordada, de maneira multilateral pelos países tornando-se uma política necessária dentro dos processos integracionistas;

- A globalização da produção cada vez mais instala-se em novos territórios, favoráveis a seu desenvolvimento. Nas últimas décadas nos deparamos com um mundo mais tecnificado no qual as velocidades da produção e da informação já não demoram muito para acontecerem;

Abrindo um parêntese é válido pensar em Desenvolvimento Regional e Infraestrutura se requer considerar a atuação das corporações, do setor produtivo ou financeiro, fomentando o desenvolvimento econômico nos locais onde estão inseridas.

- As corporações financeiras possuem importância, além disso, por serem essenciais para o funcionamento dos demais setores da economia, em que se destacam os bancos - os principais operadores das finanças e responsáveis por sua circulação;

- A função mais direta de fomento ao desenvolvimento está concentrada nas mãos dos bancos públicos que se fazem presentes em localidades economicamente menos dinâmicas e são responsáveis por levar até a população determinadas políticas públicas. É nesse contexto que o sistema bancário ganha importância como objeto a ser estudado em pesquisas geográficas; pois, a compreensão de sua forma de organização e de suas estratégias de atuação permite aos geógrafos entender qual o papel desempenhado pelas finanças na organização do espaço geográfico;

- Entre os anos 1990 e início dos anos 2000, que se intensificou o processo de internacionalização do setor bancário, no sentido de uma maior presença de bancos estrangeiros participando da financeirização do território nacional.

- Partindo da discussão sobre industrialização e a reestruturação produtiva: 
- A reestruturação produtiva, inerente ao capitalismo impõe uma determinada ordem trabalhista e produz articulações da produção industrial com o mercado e com a formação escolar, fazendo com que a educação se realize em duas direções: a da formação dos trabalhadores, quando subordina o conteúdo ensinado ao mercado e direciona ao trabalho e em outra, fonte de conhecimentos mais amplos, voltada para a classe dominante;

- No entanto, uma terceira vertente pode ser considerada no bojo dos efeitos da reestruturação produtiva e essa diz respeito à ausência ou mínima escolarização de trabalhadores, como meio de ampliação da mais valia. A história revela as diferentes interpretações sobre as formas de subsunção da educação à acumulação capitalista, iniciada com as transformações lançadas pela Revolução Industrial no final do século XVIII e a partir da qual se observou uma nova dinâmica produtiva e os seus efeitos nos cenários: social, político, econômico e educacional;

- No âmbito da reestruturação produtiva, trabalho, comportamento e cotidiano se refizeram sob novas condições, mas as principais vítimas do processo são os trabalhadores. A acumulação capitalista produz efeitos nefastos em múltiplos segmentos da vida humana e, evidentemente sobre a escolarização dos trabalhadores.

Ademais ressaltamos que a globalização da produção cada vez mais instala-se em novos territórios, favoráveis a seu desenvolvimento. Nas últimas décadas nos deparamos com um mundo mais tecnificado no qual as velocidades da produção e da informação já não demoram muito para acontecerem.

Quadro 2 - Síntese dos trabalhos apresentados no Grupo de Trabalho "Formações Socioespaciais: progresso técnico no espaço urbano e agrário" do XII Encontro Nacional da Associação Nacional de Pós-graduação e Pesquisa em Geografia (ENANPEGE) - Porto Alegre (RS)- 2017

\begin{tabular}{|l|l|l|l|l|l|}
\hline Título & $\begin{array}{l}\text { Eixos de } \\
\text { Pesquisa }\end{array}$ & Instituição & $\begin{array}{l}\text { Cidade/ } \\
\text { Estado/Região }\end{array}$ & $\begin{array}{l}\text { Nível da } \\
\text { pesquisa }\end{array}$ & Palavras-chaves \\
\hline $\begin{array}{l}\text { 1. A Análise geográfica } \\
\text { da participação do } \\
\text { ecommerce No cenário } \\
\text { Econômico brasileiro. }\end{array}$ & $* * *$ & UFU & $\begin{array}{l}\text { Uberlândia / } \\
\text { MG/CO }\end{array}$ & Docente & $\begin{array}{l}\text { Comércio Eletrônico; } \\
\text { Macroeconomia; } \\
\text { Análise Geográfica. }\end{array}$ \\
\hline $\begin{array}{l}\text { 2. A Contribuição da } \\
\text { formação socioespacial } \\
\text { quanto ao estudo das } \\
\text { Pequenas cidades. }\end{array}$ & $* * *$ & UEL & $\begin{array}{l}\text { Londrina/PR/ } \\
\text { S }\end{array}$ & $\begin{array}{l}\text { Doutorado } \\
\text { em } \\
\text { andamento }\end{array}$ & $\begin{array}{l}\text { Pequenas Cidades, } \\
\text { Rede } \\
\text { Formação Urbana, } \\
\text { Socioespacial. }\end{array}$ \\
\hline $\begin{array}{l}\text { 3. A Nova geografia das } \\
\text { bolsas de mercadorias e } \\
\text { futuros e as } \\
\text { Commodities } \\
\text { agropecuárias. }\end{array}$ & $* * *$ & UNIOESTE & $\begin{array}{l}\text { Cascavel/PR/ } \\
\text { S }\end{array}$ & $\begin{array}{l}\text { Bolsas } \\
\text { mercadorias } \\
\text { futuros; } \\
\text { commodities } \\
\text { agropecuárias; } \\
\text { capital financeiro. }\end{array}$ \\
\hline
\end{tabular}




\begin{tabular}{|c|c|c|c|c|c|}
\hline $\begin{array}{l}\text { 4. A Segunda maior } \\
\text { produção de ovos de } \\
\text { ovos do Brasil: o } \\
\text { processo } \\
\text { Estruturação de } \\
\text { avicultura de postura } \\
\text { em bases modernas de } \\
\text { Produção em santa } \\
\text { Maria de Jetibá/Espírito } \\
\text { Santo. }\end{array}$ & $* * *$ & USP & $\begin{array}{l}\text { São Paulo/SP/ } \\
\text { SE }\end{array}$ & $\begin{array}{l}\text { Doutorado } \\
\text { concluído }\end{array}$ & $\begin{array}{l}\text { Processo } r \text { de } \\
\text { trabalho, avicultura } \\
\text { de postura e } \\
\text { inovações. }\end{array}$ \\
\hline $\begin{array}{l}\text { 5. A Tecnologia uht } \\
\text { longa vida e a } \\
\text { modernização } \\
\text { conservadora na cadeia } \\
\text { Produtiva de lacteos no } \\
\text { Brasil: o caso das } \\
\text { embalagens cartonadas } \\
\text { Tetra pak e os } \\
\text { produtores de leite. }\end{array}$ & *** & UFF & Niterói/RJ/SE & $\begin{array}{l}\text { Mestrado } \\
\text { concluído }\end{array}$ & $\begin{array}{l}\text { Cadeia Produtiva; } \\
\text { UHT; Leite; }\end{array}$ \\
\hline $\begin{array}{l}\text { 6. A Topologia bancária } \\
\text { na aglomeração urbana } \\
\text { do sul (ausul) no } \\
\text { RioGrande do sul } 2003 \mathrm{~A} \\
2010 \text {. }\end{array}$ & *** & UFRGS & $\begin{array}{l}\text { Rio Grande/ } \\
\text { RS/S }\end{array}$ & $\begin{array}{l}\text { Graduação } \\
\text { concluída }\end{array}$ & $\begin{array}{l}\text { Bancos, território, } \\
\text { Ausul. }\end{array}$ \\
\hline $\begin{array}{lr}7 . & \text { Análise } \\
\text { industrialização recente } \\
\text { de cidades } \\
\text { brasileiras } & \text { pequenas } \\
\text { abordagem } & \\
\text { multiescalar. } & \end{array}$ & $* * *$ & UNESP & $\begin{array}{l}\text { São Paulo/SP/ } \\
\text { SE }\end{array}$ & $\begin{array}{l}\text { Mestrado } \\
\text { concluído }\end{array}$ & $\begin{array}{l}\text { Industrialização, } \\
\text { escalas geográficas, } \\
\text { cidades pequenas. }\end{array}$ \\
\hline $\begin{array}{l}\text { 8. As Agroindústrias da } \\
\text { mesorregião norte } \\
\text { pioneiro do Paraná: } \\
\text { Apontamentos sobre as } \\
\text { espacialidades da } \\
\text { dinâmica } \\
\text { financiamento de } \\
\text { Estrutura produtiva. }\end{array}$ & *** & UNIOESTE & $\begin{array}{l}\text { Cascavel/PR/ } \\
\mathrm{S}\end{array}$ & $\begin{array}{l}\text { Mestrado } \\
\text { em } \\
\text { andamento }\end{array}$ & $\begin{array}{l}\text { Agroindústrias; } \\
\text { espacialidades; } \\
\text { Norte Pioneiro. }\end{array}$ \\
\hline 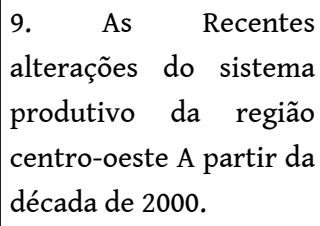 & $* * *$ & UFSC & $\begin{array}{l}\text { Florianópolis/ } \\
\mathrm{SC} / \mathrm{S}\end{array}$ & $\begin{array}{l}\text { Doutorado } \\
\text { concluído }\end{array}$ & $\begin{array}{l}\text { Centro-Oeste; } \\
\text { desenvolvimento; } \\
\text { investimentos. }\end{array}$ \\
\hline
\end{tabular}




\begin{tabular}{|c|c|c|c|c|c|}
\hline $\begin{array}{l}\text { 10. As Transformações } \\
\text { espaciais e as novas } \\
\text { relações urbano-rurais } \\
\text { No Atual contexto de } \\
\text { metropolização do } \\
\text { espaço: o exemplo do } \\
\text { bairro de Vargem } \\
\text { grande Teresópolis (RJ). }\end{array}$ & $* * *$ & PUC & $\begin{array}{l}\text { Rio de } \\
\text { Janeiro/RJ/SE }\end{array}$ & $\begin{array}{l}\text { Mestrado } \\
\text { em } \\
\text { andamento }\end{array}$ & $\begin{array}{lr}\text { Ação; } & \text { acumulação } \\
\text { por } & \text { espoliação; } \\
\text { relações } & \text { urbano- } \\
\text { rurais. } & \end{array}$ \\
\hline $\begin{array}{l}11 . \quad \text { Associações, } \\
\text { Cooperativas e o uso da } \\
\text { biodiversidade em } \\
\text { silves - AM. }\end{array}$ & $* * *$ & UFAM & $\begin{array}{l}\text { Manaus/AM/ } \\
\mathrm{N}\end{array}$ & $\begin{array}{l}\text { Doutorado } \\
\text { em } \\
\text { andamento }\end{array}$ & $\begin{array}{l}\text { Associação; } \\
\text { Cooperativa; } \\
\text { Comercialização; } \\
\text { Biodiversidade. }\end{array}$ \\
\hline $\begin{array}{l}\text { 12. Brasil e a década } \\
\text { neoliberal de } 1990 .\end{array}$ & $* * *$ & UFSC & $\begin{array}{l}\text { Florianópolis/ } \\
\mathrm{SC} / \mathrm{S}\end{array}$ & $\begin{array}{l}\text { Mestrado } \\
\text { concluído }\end{array}$ & $\begin{array}{l}\text { Brasil; } \\
\text { Neoliberalismo; } \\
\text { Desenvolvimento } \\
\text { econômico }\end{array}$ \\
\hline $\begin{array}{l}\text { 13. Cadeia Produtiva e } \\
\text { as inovações das } \\
\text { embalagens plásticas na } \\
\text { Indústria de alimentos. }\end{array}$ & $* * *$ & UFSC & $\begin{array}{l}\text { Florianópolis/ } \\
\mathrm{SC} / \mathrm{S}\end{array}$ & $\begin{array}{l}\text { Doutorado } \\
\text { em } \\
\text { andamento }\end{array}$ & $\begin{array}{l}\text { Embalagens; } \\
\text { Indústria de } \\
\text { Alimento; Indústria } \\
\text { Plástica. }\end{array}$ \\
\hline $\begin{array}{l}14 . \quad \text { Cooperativas } \\
\text { Agropecuárias } \\
\text { brasileiras e o mercado } \\
\text { global Alimentar. }\end{array}$ & $* * *$ & UFSC & $\begin{array}{l}\text { Florianópolis/ } \\
\mathrm{SC} / \mathrm{S}\end{array}$ & $\begin{array}{l}\text { Graduação } \\
\text { concluída }\end{array}$ & $\begin{array}{l}\text { Cooperativas } \\
\text { Agropecuárias; } \\
\text { Exportações; Cadeias } \\
\text { Globais Alimentares. }\end{array}$ \\
\hline $\begin{array}{l}\text { 15. Disputa Por renda } \\
\text { da terra entre } \\
\text { proprietários/ } \\
\text { produtores rurais e } \\
\text { Agroindústrias } \\
\text { sucroalcooleiras. }\end{array}$ & $* * *$ & UNESP & $\begin{array}{l}\text { São Paulo/SP/ } \\
\text { SE }\end{array}$ & $\begin{array}{l}\text { Doutorado } \\
\text { em } \\
\text { andamento }\end{array}$ & $\begin{array}{l}\text { Renda da Terra; } \\
\text { Proprietários/ } \\
\text { Produtores rurais; } \\
\text { Agroindústrias } \\
\text { Sucroalcooleiras. }\end{array}$ \\
\hline $\begin{array}{l}\text { 16. Globalização Do } \\
\text { agronegócio e novas } \\
\text { relações agro urbanas: } \\
\text { Análise inicial de } \\
\text { sorriso e Lucas do rio } \\
\text { verde-MT. }\end{array}$ & $* * *$ & UNIOESTE & $\begin{array}{l}\text { Cascavel/PR/ } \\
\mathrm{S}\end{array}$ & $\begin{array}{l}\text { Doutorado } \\
\text { em } \\
\text { andamento }\end{array}$ & $\begin{array}{l}\text { Globalização do } \\
\text { agronegócio; } \\
\text { relações } \\
\text { urbanas; progresso } \\
\text { técnico. }\end{array}$ \\
\hline $\begin{array}{l}\text { 17. Implicações } \\
\text { Territoriais da } \\
\text { agricultura de precisão } \\
\text { na região do Sudoeste } \\
\text { do Paraná. }\end{array}$ & $* * *$ & UNIOESTE & $\begin{array}{l}\text { Cascavel/PR/ } \\
\mathrm{S}\end{array}$ & $\begin{array}{l}\text { Doutorado } \\
\text { em } \\
\text { andamento }\end{array}$ & $\begin{array}{l}\text { Modernização; } \\
\text { agricultura; } \\
\text { tecnologias. }\end{array}$ \\
\hline
\end{tabular}




\begin{tabular}{|c|c|c|c|c|c|}
\hline $\begin{array}{l}\text { 18. Inovação } \mathrm{E} \\
\text { desenvolvimento } \\
\text { territorial: temas } \\
\text { emergentes para a } \\
\text { Geografia econômica } \\
\text { brasileira e latino- } \\
\text { americana. }\end{array}$ & $* * *$ & FACCAT & Taquara/RS/S & Docente & $\begin{array}{l}\text { Inovação; } \\
\text { desenvolvimento } \\
\text { territorial; geografia } \\
\text { econômica. }\end{array}$ \\
\hline $\begin{array}{l}19 . \text { Instituições } \\
\text { Executoras de ciência, } \\
\text { tecnologia e inovação } \\
\text { no norte Do Paraná. }\end{array}$ & *** & UEL & $\begin{array}{l}\text { Londrina/PR/ } \\
\mathrm{S}\end{array}$ & $\begin{array}{l}\text { Mestrado } \\
\text { concluído }\end{array}$ & $\begin{array}{l}\text { Instituições; } \\
\text { Inovação; Norte do } \\
\text { Paraná }\end{array}$ \\
\hline $\begin{array}{l}\text { 20. O Desenvolvimento } \\
\text { do setor de sementes no } \\
\text { Brasil: gênese, } \\
\text { Desenvolvimento e } \\
\text { desnacionalização. }\end{array}$ & *** & UFSC & $\begin{array}{l}\text { Florianópolis/ } \\
\mathrm{SC} / \mathrm{S}\end{array}$ & $\begin{array}{l}\text { Doutorado } \\
\text { em } \\
\text { andamento }\end{array}$ & $\begin{array}{l}\text { Setor de sementes; } \\
\text { Geografia } \\
\text { econômica; } \\
\text { Modernização da } \\
\text { agricultura. }\end{array}$ \\
\hline $\begin{array}{l}21 . \quad 0 \quad \text { Mercado } \\
\text { consumidor e a balança } \\
\text { comercial brasileira de } \\
\text { lácteos: Pós anos } 90 .\end{array}$ & *** & UFSC & $\begin{array}{l}\text { Florianópolis/ } \\
\mathrm{SC} / \mathrm{S}\end{array}$ & Docente & $\begin{array}{l}\text { Produção; } \\
\text { comercialização; } \\
\text { mercado }\end{array}$ \\
\hline $\begin{array}{l}\text { 22. Perspectiva Sócio } \\
\text { espacial da questão } \\
\text { portuária nacional. }\end{array}$ & $* * *$ & UFSC & $\begin{array}{l}\text { Florianópolis/ } \\
\mathrm{SC} / \mathrm{S}\end{array}$ & $\begin{array}{l}\text { Doutorado } \\
\text { em } \\
\text { andamento }\end{array}$ & $\begin{array}{l}\text { Portos; Navegação; } \\
\text { Desenvolvimento. }\end{array}$ \\
\hline $\begin{array}{l}\text { 23. Redes e o circuito } \\
\text { espacial superior: } \\
\text { estudo de caso no oeste } \\
\text { Catarinense. }\end{array}$ & $* * *$ & UNIOESTE & $\begin{array}{l}\text { Cascavel/PR/ } \\
\mathrm{S}\end{array}$ & $\begin{array}{l}\text { Mestrado } \\
\text { em } \\
\text { andamento }\end{array}$ & $\begin{array}{l}\text { Agroindústria da } \\
\text { Carne; Redes; Oeste } \\
\text { Catarinense. }\end{array}$ \\
\hline $\begin{array}{l}\text { 24. Transformações Na } \\
\text { política habitacional } \\
\text { brasileira a partir da } \\
\text { Financeirização da } \\
\text { habitação e das } \\
\text { políticas neoliberais. }\end{array}$ & *** & UNIOESTE & $\begin{array}{l}\text { Cascavel/PR/ } \\
\mathrm{S}\end{array}$ & Docente & $\begin{array}{l}\text { Política Habitacional } \\
\text { Brasileira; } \\
\text { Financeirização da } \\
\text { Habitação; Políticas } \\
\text { Neoliberais }\end{array}$ \\
\hline $\begin{array}{l}\text { 25. A Rede de grandes } \\
\text { corporações para a } \\
\text { promoção da inovação } \\
\text { aberta: O } \\
\text { telefônica. }\end{array}$ & $* * *$ & UEL & $\begin{array}{l}\text { Londrina/PR/ } \\
\mathrm{S}\end{array}$ & $\begin{array}{l}\text { Mestrado } \\
\text { concluído }\end{array}$ & $\begin{array}{l}\text { Inovação aberta, } \\
\text { empresa-rede, } \\
\text { Telefônica Open } \\
\text { Future }\end{array}$ \\
\hline $\begin{array}{l}\text { 26. A "dança do } \\
\text { capital": ensaios sobre } \\
\text { sua influência no setor } \\
\text { calçadista do município } \\
\text { de campo bom - RS. }\end{array}$ & $* * *$ & UFRGS & $\begin{array}{ll}\text { Rio grande/ } \\
\text { RS/S }\end{array}$ & $\begin{array}{l}\text { Graduação } \\
\text { Concluída }\end{array}$ & $\begin{array}{l}\text { Indústria Calçadista; } \\
\text { Sistema de produção } \\
\text { capitalista } \text { Fordista; } \\
\text { Sistema de produção } \\
\text { capitalista r de } \\
\text { Acumulação }\end{array}$ \\
\hline
\end{tabular}




\begin{tabular}{|c|c|c|c|c|c|}
\hline $\begin{array}{l}\text { 27. A Dimensão espacial } \\
\text { da competitividade } \\
\text { produtiva: uma análise } \\
\text { da Indústria } \\
\text { catarinense de calçados } \\
\text { à luz das } \\
\text { especializações } \\
\text { Territoriais produtivas } \\
\text { (E.T.P.S). }\end{array}$ & $* * *$ & UFSC & $\begin{array}{l}\text { Florianópolis/ } \\
\mathrm{SC} / \mathrm{S}\end{array}$ & $\begin{array}{l}\text { Doutorado } \\
\text { em } \\
\text { andamento }\end{array}$ & $\begin{array}{l}\text { Desenvolvimento } \\
\text { regional; } \\
\text { Especializações } \\
\text { Territoriais } \\
\text { Produtivas; } \\
\text { Geografia } \\
\text { Econômica. }\end{array}$ \\
\hline $\begin{array}{l}\text { 28. O Município de } \\
\text { Teixeira de Freitas e a } \\
\text { formação socioespacial } \\
\text { do Extremo sul da } \\
\text { Bahia. }\end{array}$ & $* * *$ & IF & $\begin{array}{l}\text { Salvado/BA/ } \\
\mathrm{NE}\end{array}$ & Docente & $\begin{array}{l}\text { Extremo Sul da } \\
\text { Bahia. Teixeira de } \\
\text { Freitas, Formação } \\
\text { social }\end{array}$ \\
\hline
\end{tabular}

Fonte: ANAIS do XII ENCONTRO NACIONAL DA ANPEge, 2017. Org. AUtORES.

***oBS: ESSE gRUPO DE TRABALHO (GT) NÃO FOI DIVIDIDO EM EIXOS TEMÁTICOS.

41 Prosseguindo a análise do quadro 2, observamos que, numa divisão regional foram apresentados trabalhos oriundos das seguintes regiões: Sudeste (5), Sul (20), CentroOeste (1), Norte (1) e Nordeste (1). Em relação ao nível da pesquisa, temos a seguinte radiografia:

- Docentes: 6 pesquisas;

43 - Doutorado em andamento: 9 pesquisas;

44 - Doutorado concluído: 2 pesquisas;

- Mestrado concluído: 5 trabalhos;

- Mestrado em andamento: 3 estudos;

- Graduação concluída: 3 pesquisas.

Portanto, os dois níveis de pesquisa com maior representação no GT são: Doutorado em andamento com 9 pesquisas $(32,1 \%)$; e Docentes com 6 trabalhos $(21,4 \%)$; totalizando 15 pesquisas $(53,5 \%)$ do total de 28 .

As Universidades representadas no GT com 2 ou mais estudos (as demais tiveram apenas um trabalho apresentado), por ordem decrescente do número de pesquisas são:

1. Universidade Federal de Santa Catarina: 8;

2. Universidade Estadual do Oeste do Paraná: 6;

3. Universidade Estadual de Londrina: 3;

4. Universidade Federal do Rio Grande do Sul: 2;

5. Universidade Estadual Paulista: 2.

No caso desse GT por não tratar-se de eixos temáticos a análise qualitativa será ponderada de uma forma unificada dos trabalhos.

$\mathrm{O}$ tema pequenas cidades embora tenha sido até o último quartel do século XX, pouco estudado no âmbito da geografia brasileira, tem paulatinamente despertado o interesse dos pesquisadores, em decorrência da especialização funcional que muitas dessas cidades têm apresentado e também, devido às mudanças decorridas da complexificação 
das relações econômicas e sociais, manifestas quanto ao seu papel na rede urbana a qual se inserem. Logo, com o intuito de compreender o que são as pequenas cidades e suas funções, têm-se atrelado seu estudo à rede urbana a qual se inserem, pois embora sejam itens numerosos em tal contexto, podem apresentar especificidades, resultantes da divisão territorial do trabalho.

- Além das reflexões relativas ao conceito da formação socioespacial, observou-se que a discussão da formação socioespacial nem sempre atrela-se à uma análise social do espaço, considerando a produção do mesmo, existindo posicionamentos que fazem apenas reconstruções teóricas do conceito de formação socioespacial, porém, o estudo da formação socioespacial deve ir além disso, buscando atrelar-se à compreensão da rede urbana e das pequenas cidades, ou seja, deve ser usado e aplicado como um método, uma vez que mostrase capaz de auxiliar na compreensão da produção do espaço e por consequência, a rede urbana.

\section{Outro tema relevante a ser ressaltado é:}

- Atualmente, os processos industriais de lácteos no Brasil são frutos das mudanças tecnológicas no contexto da globalização econômica mundial iniciada a partir da década de 1970 e que chegou ao Brasil na década de 1990, pela chamada abertura econômica neoliberal. A globalização econômica é caracterizada pelas novas tecnologias informacionais que baratearam as comunicações e os transportes em nível mundial. Com a adoção da tecnologia de envasamento $\mathrm{UHT}^{1}$, houve uma transformação na cadeia de frios brasileira que conseguiu abrir mão de tecnologia de resfriamento nos transportes para dar lugar ao transporte e envasamento de leite fluido em temperatura ambiente com prazo de validade superestendido.

58 Abrindo um parêntese para algumas cidades pequenas brasileiras à condição de receptoras de grandes capitais da indústria:

- A globalização é responsável por diversas reestruturações nas esferas social, econômica, política, cultural, e espacial da sociedade contemporânea. No caso da atividade produtiva, o acirramento da competição intercapitalista, o desenvolvimento tecnológico e a articulação mais estreita entre os lugares fortaleceram a internacionalização do capital produtivo, a segmentação setorial e espacial da produção e a extração global de mais-valia;

- Como consequência, intensificaram-se as forças centrífugas sobre áreas tradicionais de concentração industrial, alterando os padrões de localização das unidades produtivas e o direcionamento dos fluxos industriais nas diferentes escalas geográficas;

- Esta tendência acentua-se na década de 1990, fruto de conjuntura político-econômica específica marcada pela abertura e desregulamentação dos mercados nacionais, pela disseminação de práticas neoliberais, e pela aceleração e maior densidade das trocas materiais e imateriais pelo mundo. É nesse cenário que algumas cidades pequenas, tradicionalmente concebidas como últimos elos da confluência urbano-rural, passaram a receber expressivas somas de investimentos industriais exógenos (nacionais e/ou estrangeiros), que nelas engendraram um ciclo de crescimento industrial e econômico. Novas dinâmicas socioespaciais perpassaram o território destas cidades, modificando-lhes os conteúdos e transformando-lhes a paisagem.

\section{CONSIDERAÇÕES FINAIS}

Portanto, este artigo aponta para a relevância da geografia econômica nas reflexões expostas junto ao estudo da arte, no qual o estado da arte refere-se a uma atividade 
árdua e complexa, justamente por seu caráter crítico e reflexivo, auxiliando na otimização e, também, no desenvolvimento de novas demandas de pesquisa, conceitos e paradigmas. Segundo CHORINCAS (2001, p.30):

Arriscamo-nos a acreditar que se assistiu recentemente à inevitável aceitação da Geografia Económica no seio da Comunidade Científica. Inevitável porque, por um lado, a Economia exerce (e continuará a exercer) uma forte influência nas metodologias e teorias desenvolvidas no seio da ciência geográfica - de facto, muitos aspectos que os geógrafos se propõem analisar e interpretar têm uma dimensão económica. De modo semelhante, muitos fenómenos abordados pelos economistas têm uma dimensão espacial.

Ressaltamos que todos os eixos temáticos possuem sua importância e seu papel dentro do pilar das pesquisas em educação do qual fazem parte. Salientamos os quão variados aspectos a geografia econômica se insere, pois além do estudo da localização, distribuição e organização espacial das atividades econômicas na terra abrangem tópicos como transporte, agricultura, localização industrial, comércio internacional e a organização espacial.

\section{BIBLIOGRAFIA}

ANPEGE. Anais do XII Encontro Nacional da ANPEGE. Presidente Prudente: UFGD Editora, 2017.

CHORINCAS, J. Geografia Econômica: Encontros e Desencontros de uma ciência de

Encruzilhada. Inforgeo, 16/17, Lisboa, EdiçõesColibri, p. 109-122, 2001/02.

FERREIRA, N. S. de A. As pesquisas denominadas "estado da arte". Educação \& Sociedade, Campinas, ano XXIII, no. 79, p. 257-272, 2002.

HADDAD, S. Educação de Jovens e Adultos no Brasil (1986-1998). Brasília: MEC/INEP, COMPED, 2002 (Série Estado do Conhecimento no. 8).

\section{NOTAS}

1. UHT é sigla para "ultra high temperature" que significa temperatura ultra alta. É um processo utilizado para esterilização de alimentos através do aquecimento e, imediatamente a seguir, do resfriamento. 


\section{RESUMOS}

$\mathrm{O}$ artigo tem como intuito principal apontar a pesquisa sobre as principais contribuições dos estudos de Geografia Econômica e como o estado da arte reflete nesses trabalhos publicados nos anais do XII Encontro Nacional da Associação Nacional de Pós-graduação e Pesquisa em Geografia (ENANPEGE), realizado na cidade de Porto Alegre (RS), no período de 12 a 15 de outubro de 2017. Os trabalhos dessa subárea da Ciência Geográfica encontram-se em dois grupos de Trabalhos (GTs): "Desenvolvimento Regional e Infraestrutura" - com a publicação de 28 trabalhos completos; "Formações Socioespaciais: progresso técnico no espaço urbano e agrário" - com a publicação de 28 trabalhos completos. Os trabalhos do primeiro GT estiveram distribuídos em cinco eixos centrais: 1) Circulação, transportes e logística; 2) Financeirização do território nacional e internacionalização da economia brasileira; 3) Políticas públicas e desenvolvimento regional; 4) Desenvolvimento econômico, política industrial e comércio exterior; 5) Agronegócio e circuitos espaciais da produção. O segundo GT, não foi dividido em eixos temáticos. Para a construção do mesmo, foram feitas as seguintes etapas: leitura e análise dos 56 trabalhos publicados, leitura de referencial teórico sobre os temas da geografia econômica. Por fim, por ser uma atividade difícil e complexa, o Estado da arte detém caráter crítico e reflexivo; contribuindo, dessa forma, no desenvolvimento de novas demandas de pesquisa, conceitos e paradigmas.

The main purpose of this article is to point out the research on the main contributions of the studies of Economic Geography and how the state of the art reflects in these works published in the annals of the XII National Meeting of the National Association of Geography Graduate Research (ENANPEGE), held in the city of Porto Alegre (RS), from October 12 to 15, 2017. The works of this subarea of Geographic Science are in two Groups of WGs: "Regional Development and Infrastructure" - with the publication of 28 completed works; "Socio-spatial Formations: Technical Progress in Urban and Agrarian Space" - with the publication of 28 completed works. The work of the first WG was distributed in five central axes: 1) Circulation, transport and logistics; 2) Financialization of the national territory and internationalization of the Brazilian economy; 3) Public policies and regional development; 4) Economic development, industrial policy and foreign trade; 5) Agribusiness and spatial circuits of production. The second WG was not divided into thematic axes. For its construction, the following steps were made: reading and analysis of the 56 published papers, reading of theoretical framework on the themes of economic geography. Finally, as a difficult and complex activity, the state of the art has a critical and reflexive character; thus contributing to the development of new research demands, concepts and paradigms.

El objetivo principal de este artículo es señalar la investigación sobre las principales contribuciones de los estudios de Geografía Económica y cómo se refleja el estado del arte en estos trabajos publicados en los anales de la XII Reunión Nacional de la Asociación Nacional de Investigación de Graduados en Geografía (ENANPEGE) , celebrada en la ciudad de Porto Alegre (RS), del 12 al 15 de octubre de 2017. Los trabajos de esta subárea de Ciencias Geográficas se encuentran en dos Grupos de GT: "Desarrollo e Infraestructura Regional" - con la publicación de 28 obras terminadas; "Formaciones socio-espaciales: progreso técnico en el espacio urbano y agrario", con la publicación de 28 trabajos terminados. El trabajo del primer WG se distribuyó en cinco ejes centrales: 1) Circulación, transporte y logística; 2) Financialización del territorio nacional e internacionalización de la economía brasileña; 3) Políticas públicas y desarrollo regional; 4) Desarrollo económico, política industrial y comercio exterior; 5) Agronegocios y circuitos espaciales de producción. El segundo GT no se dividió en ejes temáticos. Para su construcción, se tomaron los siguientes pasos: lectura y análisis de los 56 artículos publicados, 
lectura del marco teórico sobre los temas de la geografía económica. Finalmente, como una actividad difícil y compleja, el estado de la técnica tiene un carácter crítico y reflexivo; Contribuyendo así al desarrollo de nuevas demandas de investigación, conceptos y paradigmas.

Le but principal de cet article est de mettre en évidence les recherches sur les principales contributions des études de géographie économique et comment l'état de l'art se reflète dans ces travaux publiés dans les annales de la XII réunion nationale de l'Association nationale des études supérieures et de recherche géographique (ENANPEGE). , qui s'est tenue dans la ville de Porto Alegre (RS), du 12 au 15 octobre 2017. Les travaux de cette sous-zone des sciences géographiques sont divisés en deux groupes de travail (GT): «Développement régional et infrastructure» - avec le publication de 28 œuvres achevées; «Formations socio-spatiales: progrès technique dans l'espace urbain et agraire» - avec la publication de 28 travaux achevés. Les travaux du premier GT ont été répartis sur cinq axes centraux: 1) Circulation, transport et logistique; 2) la financiarisation du territoire national et l'internationalisation de l'économie brésilienne; 3) Politiques publiques et développement régional; 4) Développement économique, politique industrielle et commerce extérieur; 5) Agroalimentaire et circuits spatiaux de production. Le deuxième GT n'a pas été divisé en axes thématiques. Pour sa construction, les étapes suivantes ont été franchies: lecture et analyse des 56 ouvrages publiés, lecture de référence théorique sur les thèmes de la géographie économique. Enfin, en tant qu'activité difficile et complexe, l'état de l'art a un caractère critique et réflexif; contribuant ainsi au développement de nouvelles demandes, concepts et paradigmes de recherche.

\section{ÍNDICE}

Mots-clés: état de l'art, développement régional, infrastructures, formations socio-spatiales, Enanpege 2017

Palavras-chave: Estado da Arte, Desenvolvimento Regional, Infraestrutura, Formações Socioespaciais, Enanpege 2017.

Palabras claves: Estado del Arte, Desarrollo Regional, Infraestructura, Formaciones Socioespaciales, Enanpege 2017.

Keywords: State of Art, Regional Development, Infrastructure, Socio-spatial formations, Enanpege 2017.

\section{AUTOR}

\section{IZABELLE DE OLIVEIRA FELEZ}

Graduanda em Licenciatura em Geografia pela UNICENTRO (PR) e Bolsista de Iniciação Científica (FA) - Área: Geografia Econômica

E-mail: Izabellefelez@gmail.com 